\title{
An evaluation of an operations research project to reduce childhood stunting in a food-insecure area in Ethiopia
}

\author{
Bridget Fenn ${ }^{1, *}$, Assaye T Bulti ${ }^{2}$, Themba Nduna ${ }^{2}$, Arabella Duffield ${ }^{2}$ and \\ Fiona Watson ${ }^{3}$ \\ 'Le Rocher, 61210 La Foret Auvray, France: ${ }^{2}$ Save the Children, Addis Ababa, Ethiopia: ${ }^{3}$ Save the Children, \\ London, UK
}

Submitted 18 June 2011: Final revision received 6 March 2012: Accepted 6 March 2012: First published online 17 April 2012

\begin{abstract}
Objective: To determine which interventions can reduce linear growth retardation (stunting) in children aged 6-36 months over a 5-year period in a food-insecure population in Ethiopia.

Design: We used data collected through an operations research project run by Save the Children UK: the Child Caring Practices (CCP) project. Eleven neighbouring villages were purposefully selected to receive one of four interventions: (i) health; (iii) nutrition education; (iii) water, sanitation and hygiene (WASH); or (iv) integrated comprising all interventions. A comparison group of three villages did not receive any interventions. Cross-sectional surveys were conducted at baseline (2004) and for impact evaluation (2009) using the same quantitative and qualitative tools. The primary outcome was stunted growth in children aged 6-36 months measured as height (or length)-for-age Z-scores (mean and prevalence). Secondary outcomes were knowledge of health seeking, infant and young child feeding and preventive practices.

Setting: Amhara, Ethiopia.

Subjects: Children aged 6-36 months.

Results: The WASH intervention group was the only group to show a significant increase in mean height-for-age $Z$-score $(+0 \cdot 33, P=0 \cdot 02)$, with a $12 \cdot 1 \%$ decrease in the prevalence of stunting, compared with the baseline group. This group also showed significant improvements in mothers' knowledge of causes of diarrhoea and hygiene practices. The other intervention groups saw non-significant impacts for childhood stunting but improvements in knowledge relating to specific intervention education messages given.

Conclusions: The study suggests that an improvement in hygiene practices had a significant impact on stunting levels. However, there may be alternative explanations for this and further evidence is required.
\end{abstract}

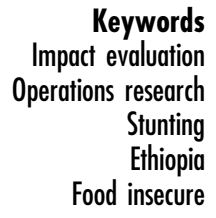

Protecting children from stunted growth during the first 2 years of life is critical for their future development. Childhood malnutrition is a major public health problem in low-income countries; about $20 \%$ of childhood mortality is associated with stunting or underweight ${ }^{(1)}$. Inadequate nutrition during the first 2 years of life causes irreparable damage through impeding physical and cognitive growth. Stunted children complete fewer years of schooling and as adults have reduced work capacity, earn less income and have poorer health ${ }^{(1,2)}$. Averting stunting during this early period is crucial and evidence suggests that younger children are more responsive to interventions to address nutritional problems ${ }^{(3,4)}$. Information from communitybased programmes aimed at this younger age group is scarce, however, and especially so in sub-Saharan Africa.
The Legambo Child Caring Practices (CCP) project was set up in 2004. A full description of the CCP has been previously documented ${ }^{(5)}$. The CCP was an operations research project aiming to improve young children's nutritional status and measure the effectiveness of different interventions, singularly and in combination, on childhood growth in a food-insecure area. While the association between poverty and stunting is well established ${ }^{(6)}$, there is limited evidence on which single interventions can effectively prevent early childhood stunting or whether an integrated package incorporating different interventions is more effective.

The interventions for the CCP project were selected on the basis of known effective interventions as well as previous research carried out in an area very similar to the 


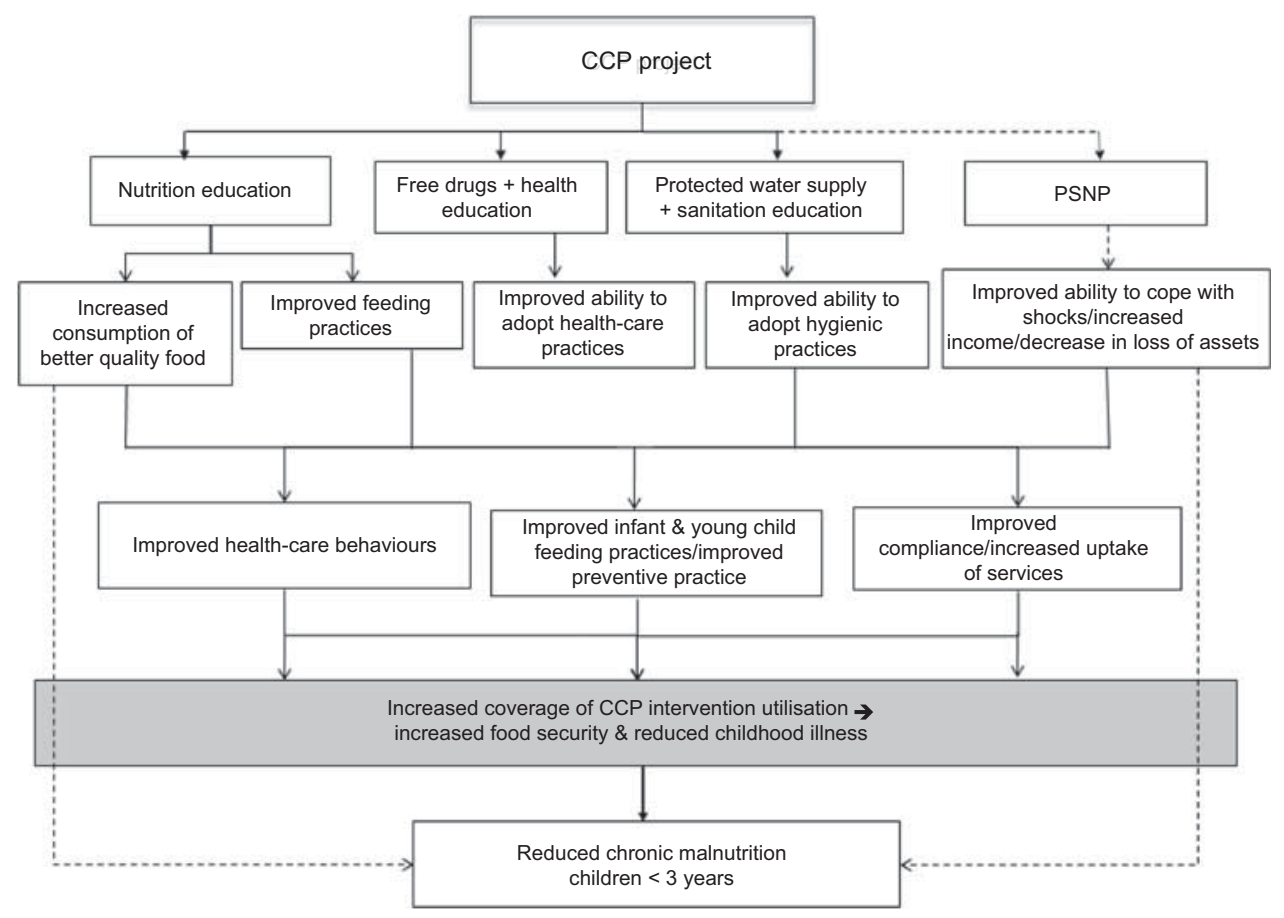

Fig. 1 Child Caring Practices (CCP) project causal framework for reducing stunting in children (PSNP, Productive Safety Net Programme)

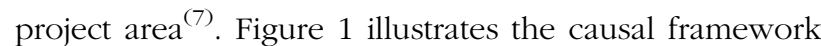
for the CCP programme and shows the pathways through which a reduction in the prevalence of childhood stunting was to be achieved.

\section{Experimental methods}

\section{Project area}

The CCP project took place in Legambo woreda (an administrative district), South Wollo Zone, Amhara Region, Ethiopia, with a population of 164 964. The main livelihood in the project area is agricultural, with some agro-pastoralism. Agriculture is predominantly belg-rain dependent (a short rainfall that occurs between February and May). The district is divided into thirty-three villages (communities), which are further divided into smaller rural gotts (sub-villages). Since 1996/97 Legambo has suffered a number of droughts resulting in both loss of crops and livestock and heavy reliance on relief food. Stunting rates are very high in the more mountainous areas of the district where over $60 \%$ of children less than 5 years old have been recorded as stunted ${ }^{(8)}$.

A number of programmes were running in Legambo during the study period. The Government of Ethiopia initiated a Productive Safety Net Programme (PSNP) in 2004 through which food-insecure households are targeted to receive either a cash or grain transfer ${ }^{(9)}$. The Government also began a community-based health-care delivery system where a network of health extension workers, trained in a 1-year programme, deliver a package of sixteen health-care activities (mainly health messages) at the village level ${ }^{(10)}$. In addition, emergency programmes had been implemented during crisis periods in Legambo. These included general ration distribution, supplementary and therapeutic feeding programmes that aim to prevent and treat acute malnutrition in children.

\section{Procedures and participants}

Selected contiguous communities, geographically defined villages with similar livelihoods, were purposefully, rather than randomly assigned, to receive one of four interventions: (i) health; (ii) nutrition education; (iii) water, sanitation and hygiene (WASH); or (iv) integrated comprising all three interventions. A total of eleven villages, out of the thirty-three, were selected with similar demographic, socio-economic and livelihood profiles. The health and integrated interventions were assigned to villages close to a functioning health centre. The WASH intervention was assigned to villages that had been specifically identified by local authorities as having poor access to water sources. The nutrition and comparison interventions were assigned to the remaining five villages.

The interventions were mainly educational, although free drugs and primary health-care services were provided for the health and integrated intervention groups, and materials such as pit latrines and clean water sources were constructed in WASH intervention areas. Community demonstration gardens were set up in the nutrition 
Table 1 Description of the interventions

\begin{tabular}{|c|c|c|}
\hline Group & Intervention & Primary target group \\
\hline 1. Nutrition & $\begin{array}{l}\text { - Nutrition and health education: feeding practices (breast-feeding, } \\
\text { complementary feeding, food diversity and frequency), mother's } \\
\text { nutrition during pregnancy and lactation, diarrhoea (causes, } \\
\text { symptoms and treatment) and immunisation } \\
\text { - PSNP }\end{array}$ & $\begin{array}{l}\text { Pregnant mothers and carers } \\
\text { of children }<2 \text { years }\end{array}$ \\
\hline 2. Health & $\begin{array}{l}\text { - Free essential drugs and micronutrients for mother and children } \\
\text { and health education: vaccination, family planning, antenatal } \\
\text { care, postnatal care, safe delivery, common childhood illness } \\
\text { and treatment } \\
\text { - PSNP }\end{array}$ & All children $<5$ years \\
\hline 3. WASH & $\begin{array}{l}\text { - Protected water supply } \\
\text { - Sanitation education: personal and environmental hygiene practices } \\
\text { (soap use, hand-washing practices, sanitary facility construction, } \\
\text { cleanliness of house and construction of separate housing for } \\
\text { animals, keeping water clean) } \\
\text { - PSNP }\end{array}$ & Entire community (water supply) \\
\hline 4. Integrated & $\begin{array}{l}\text { - All components } \\
\text { - PSNP }\end{array}$ & All of the above \\
\hline 5. Comparison & - PSNP only & Poorest households \\
\hline
\end{tabular}

PSNP, Productive Safety Net Programme; WASH, water, sanitation and hygiene.

education intervention group. A fifth group was used for comparison purposes but did not receive any of the Save the Children UK interventions. All five groups were covered by ongoing Government programmes and services. The interventions are summarised in Table 1.

Educational messages were delivered door-to-door by trained community animators for all interventions. The health and integrated groups received home-based messages $10 \mathrm{~d}$ every month. The nutrition and WASH groups received home-based messages $5 \mathrm{~d}$ every month and received a further $5 \mathrm{~d}$ centre-based education session.

The project's main aim was to reduce the retardation in linear growth in children aged 6-36 months. Since stunting disproportionately affects children in poorer households, the interventions were prioritised to caregivers with a child or children less than 3 years of age or who were pregnant or lactating and were PSNP beneficiaries. As with many community-based interventions, however, it was difficult to exclude some members of the community and as such the inclusion criteria were not strictly adhered to. For example, while interventions were aimed primarily at PSNP beneficiaries no one was excluded from the education sessions or door-to-door visits; in the health intervention areas all households with children under the age of 5 years and pregnant and lactating women were included; in the WASH group, all members of the community were involved as it would have been too difficult to exclude other members of the community from accessing clean water from the protected springs.

The evaluation survey was carried out between July and September 2009; the baseline survey was conducted at the beginning of the project in October to December 2004. Both baseline and evaluation surveys were crosssectional, selecting different children each time, and used exhaustive door-to-door case-finding to find all households with children less than 3 years of age. The same quantitative and qualitative data collection methods and tools were used. Contextual information was also collected during the evaluation survey to estimate the extent that external project factors had, if any, on the observed outcomes. A full report of the impact assessment is available ${ }^{(11)}$.

The main outcomes estimated were the difference in mean height (length)-for-age $Z$-score and prevalence of stunting in children aged 6-36 months. Stunting was measured using the indicator height-for-age or length-forage for children less than 2 years (or less than $85 \mathrm{~cm}$ ). This indicator is measured in $Z$-scores that equate to standard deviations from the median of a reference population, which in this case is the WHO growth standards ${ }^{(12)}$. Children with a height (length)-for-age $Z$-score (HAZ) less than -2 are termed 'stunted'.

Secondary outcomes of interest were health-seeking practices, infant and young child feeding practices and improved preventive practice. Health-seeking practices were assessed by estimating behavioural changes towards the care of sick children (knowledge and practice), illness management and use of health-care services. Infant and child feeding practices were assessed by knowledge and practice and preventive practice by hygiene practices, access to soap, a toilet and safe water.

Height (length)-for-age measurements were estimated in all children aged 6-36 months. Data collectors were trained using SMART (Standardised Monitoring \& Assessment of Relief \& Transitions) guidelines ${ }^{(13)}$ and standardisation tests were carried out using the Emergency Nutrition Assessment (ENA) software ${ }^{(14)}$ standardisation function. Height was measured using locally constructed boards with rigid headboard and moveable foot-base with a precision of $1 \mathrm{~mm}$. 
Weight (undressed) was measured with $25 \mathrm{~kg}$ Salter scales with precision to $100 \mathrm{~g}$. Scales were routinely calibrated against a known weight. Mid upper-arm circumference (MUAC) using standard MUAC bands with precision to $1 \mathrm{~mm}$ were used for both children and mothers. Age was identified through both birth certification and seasonal calendar.

\section{Statistical analyses}

The database for all questionnaires was created in Microsoft ${ }^{\circledR}$ Access 2007 (Microsoft Corporation, Redmond, WA, USA) and anthropometric $Z$-scores were created using ENA software. Data were double entered by two different data-entry clerks on the following day and any discrepancies were checked with the original forms. Data were imported, merged (baseline and evaluation data sets) and analysed in the STATA statistical software package version 10 (StataCorp, College Station, TX, USA). Qualitative data were transcribed at the end of each data collection day.

Composite variables were constructed by either summing or scoring data collected in both rounds: mother's knowledge from information about appropriate feeding practices and knowledge and treatment of diarrhoea; diarrhoea knowledge from the different causes of diarrhoea given; dietary diversity was adapted from Ruel scores $^{(15)}$; the hygiene score from observations of hygiene practices, i.e. whether the household had a tap, a clean compound, the presence of animal faeces in and around the house and water storage covering facility; access to safe water was water from a protected water source that took less than 30 min return time.

Bivariable analyses were carried out to estimate associations between explanatory variables and stunting. For categorical variables tests for difference between two proportions using $\chi^{2}$ statistics over time were used, and for quantitative variables $t$ tests to estimate differences between means over time were used.

Linear regression models for mean $Z$-scores (and linear probability regression models for binary outcomes), with robust standard errors to account for clustering at community level, were used with interaction terms for time (baseline $v$. evaluation) and intervention to test the null hypothesis that the difference-in-difference (between intervention and comparison groups over time) equalled zero, controlling for child sex and age, mother's age, mother's MUAC and wealth for stunting; and mother's age, mother's education and wealth for all other secondary outcomes. Mother's education was not a predictor for stunting in the present study so was not included in the model. Morbidity data, although collected, were also not considered due to seasonal effects from surveys carried out at different times of the year. An interaction term measuring differential effects of wealth in the intervention and comparison groups was also included in the regression analysis. It was assumed that the composition of the intervention and comparison populations was similar at baseline as well as stable over time and that any observed differences in the analysis reflected the changes due to the intervention rather than unobserved characteristics within the population.

\section{Etbical approval}

The CCP programme received approval from the Government of Ethiopia, Amhara regional bureaus: Bureau of Food Security Programme Co-ordination and Disaster Prevention; Bureau of Water Resource Development; and Bureaus of Health. Consent was gained verbally from each village leader and also from mothers or caregivers at household level prior to every interview.

\section{Results}

Baseline characteristics of households and children for each intervention group compared with the comparison group are presented in Table 2. Intervention groups were broadly similar to the comparison group at baseline. In the baseline study there were 5552 children (comparison $n$ 1428; nutrition $n$ 1081; health $n$ 1081; WASH $n 1048$; integrated $n$ 914). In the evaluation study there were 3758 children (comparison $n$ 1036; nutrition $n 683$; health $n 597$; WASH $n 863$; integrated $n$ 579).

Table 3 shows a significant increase in mean HAZ in children aged 6 to 36 months between 2004 and 2009 in the WASH group compared with the comparison group. The other intervention groups did not show any significant impact on stunting. Figure 2 illustrates the direction and magnitude of the difference in stunting prevalence for the intervention groups. In the WASH group there was a $12 \cdot 1 \%$ decrease in stunting prevalence.

Differences in secondary outcomes are shown in Table 4. There were directional differences of varying magnitudes relative to the comparison group over time. The health and integrated groups showed significant increases in health seeking for treatment of disease. The nutrition and integrated groups had the largest improvements in both breast-feeding knowledge and practice and complementary feeding knowledge.

The WASH group had the largest improvements in hygiene score and access to soap. All groups showed significantly increased knowledge about the causes of diarrhoea and three of the intervention groups, with the exception of the WASH group, experienced significant improvements in mother's knowledge about appropriate feeding practices when the child had diarrhoea. Dietary diversity did not differ significantly over time for any group except for the WASH group, which recorded a decrease in diversity.

Some unexpected results were observed. There was a significant improvement in access to safe water in the integrated group only and not in the WASH group despite investment in water and sanitation. There was also no significant improvement in access to toilets in the WASH 
Table 2 Comparison of selected baseline characteristics between comparison and intervention groups, Amhara, Ethiopia

\begin{tabular}{|c|c|c|c|c|c|c|c|c|c|c|}
\hline & \multicolumn{10}{|c|}{ Interventions } \\
\hline & \multicolumn{2}{|c|}{ Comparison } & \multicolumn{2}{|c|}{ Nutrition } & \multicolumn{2}{|c|}{ Health } & \multicolumn{2}{|c|}{ WASH } & \multicolumn{2}{|c|}{ Integrated } \\
\hline & $n$ or Mean & $\%$ or SD & $n$ or Mean & $\%$ or SD & $n$ or Mean & $\%$ or SD & $n$ or Mean & $\%$ or SD & $n$ or Mean & $\%$ or SD \\
\hline \multicolumn{11}{|l|}{ Household } \\
\hline \multicolumn{11}{|l|}{ Wealth } \\
\hline 1 (poorest) & 310 & $23 \cdot 1$ & 195 & $19 \cdot 0$ & 163 & $16 \cdot 7$ & 170 & $17 \cdot 4$ & 95 & $11 \cdot 0$ \\
\hline 2 (poor) & 519 & $38 \cdot 6$ & 321 & $31 \cdot 4$ & 363 & $37 \cdot 1$ & 314 & $32 \cdot 0$ & 333 & $38 \cdot 7$ \\
\hline 3 (medium) & 346 & $25 \cdot 8$ & 381 & $37 \cdot 2$ & 353 & $36 \cdot 1$ & 367 & $37 \cdot 5$ & 312 & $36 \cdot 2$ \\
\hline 4 (better off) & 168 & $12 \cdot 5$ & 127 & $12 \cdot 4$ & 100 & $10 \cdot 2$ & $129^{\star *}$ & $13 \cdot 2$ & $121^{\star \star}$ & $14 \cdot 1$ \\
\hline Household sizet & $5 \cdot 5$ & $1 \cdot 6$ & $5 \cdot 6$ & $1 \cdot 7$ & $5 \cdot 4^{\star *}$ & 1.5 & $5 \cdot 2^{\star \star \star}$ & 1.5 & $5 \cdot 5$ & 1.5 \\
\hline $\begin{array}{l}\text { Number of children }<5 \text { years } \\
\text { in householdt }\end{array}$ & $1 \cdot 3$ & 0.5 & $1 \cdot 4$ & $0 \cdot 6$ & $1 \cdot 5^{\star \star \star}$ & $0 \cdot 6$ & $1 \cdot 3$ & 0.5 & $1 \cdot 4^{\star \star \star}$ & $0 \cdot 6$ \\
\hline Mother's age (years) $\dagger$ & $28 \cdot 7$ & $6 \cdot 0$ & $28 \cdot 6$ & $6 \cdot 5$ & $28 \cdot 6$ & $6 \cdot 5$ & $29 \cdot 4$ & $6 \cdot 0$ & $28 \cdot 4$ & $6 \cdot 1$ \\
\hline \multicolumn{11}{|l|}{ Mother's schooling } \\
\hline None & 1154 & $87 \cdot 9$ & 762 & $76 \cdot 3$ & 789 & $81 \cdot 7$ & 892 & $91 \cdot 6$ & 734 & $87 \cdot 0$ \\
\hline Informal & 85 & $6 \cdot 5$ & 100 & $10 \cdot 0$ & 105 & $10 \cdot 9$ & 35 & $3 \cdot 6$ & 51 & $6 \cdot 0$ \\
\hline Primary (or higher) & 74 & $5 \cdot 6$ & $137^{\star *}$ & $13 \cdot 7$ & $72^{\star \star \star}$ & $7 \cdot 5$ & $47^{\star \star \star}$ & $4 \cdot 8$ & 59 & $7 \cdot 0$ \\
\hline \multicolumn{11}{|l|}{ Child } \\
\hline Age (months) $\dagger$ & $18 \cdot 0$ & $10 \cdot 4$ & $17 \cdot 3$ & $9 \cdot 9$ & $19 \cdot 0$ & $10 \cdot 3$ & $17 \cdot 0$ & $10 \cdot 5$ & $17 \cdot 9$ & $10 \cdot 9$ \\
\hline \multicolumn{11}{|l|}{ Sex } \\
\hline Girl & 745 & $52 \cdot 2$ & 534 & $49 \cdot 4$ & 536 & $49 \cdot 6$ & 539 & $51 \cdot 4$ & 456 & $49 \cdot 9$ \\
\hline $\begin{array}{l}\text { Boy } \\
\text { HAZ }\end{array}$ & 683 & $47 \cdot 8$ & $547^{*}$ & $50 \cdot 6$ & 545 & $50 \cdot 4$ & 509 & $48 \cdot 6$ & 458 & $50 \cdot 1$ \\
\hline$<-2$ & 703 & $62 \cdot 4$ & 494 & $61 \cdot 4$ & 504 & $59 \cdot 8$ & 503 & $64 \cdot 3$ & 430 & $62 \cdot 5$ \\
\hline$<-3$ & 328 & $29 \cdot 1$ & 261 & $32 \cdot 5$ & 257 & $30 \cdot 5$ & 238 & $30 \cdot 4$ & 223 & $32 \cdot 4$ \\
\hline Meant & $-2 \cdot 36$ & $1 \cdot 18$ & $-2 \cdot 37$ & $1 \cdot 21$ & $-2 \cdot 31$ & $1 \cdot 28$ & $-2 \cdot 43$ & $1 \cdot 16$ & $-2 \cdot 41$ & $1 \cdot 23$ \\
\hline
\end{tabular}

WASH, water, sanitation and hygiene; HAZ, height (length)-for-age Z-score.

Value was significantly different from that of the comparison site with robust standard errors adjusting for clustering at village level $\left(\chi^{2}\right.$ test for difference in proportions and $t$ test for difference in means): ${ }^{*} P<0.05,{ }^{* *} P<0.01,{ }^{* *} P<0.001$.

tThese data are presented as mean and standard deviation; otherwise, data are number and percentage.

Table 3 Adjusted and unadjusted differences between baseline and evaluation surveys for each intervention group compared with the comparison group for mean height-for-age Z-score, children aged 6-36 months, Amhara, Ethiopia

\begin{tabular}{|c|c|c|c|c|c|c|c|c|c|c|}
\hline \multirow[b]{2}{*}{ Intervention } & \multicolumn{2}{|c|}{ Baseline } & \multicolumn{2}{|c|}{ Evaluation } & \multicolumn{2}{|c|}{ Unadjusted difference } & \multirow[b]{2}{*}{$P$ value } & \multicolumn{2}{|c|}{ Adjusted differencet } & \multirow[b]{2}{*}{$P$ value } \\
\hline & Mean & SD & Mean & SD & Mean & $95 \% \mathrm{Cl}$ & & Mean & $95 \% \mathrm{Cl}$ & \\
\hline Nutrition & $-2 \cdot 37$ & $1 \cdot 21$ & $-2 \cdot 26$ & $1 \cdot 18$ & 0.08 & $-0.08,0.25$ & $0 \cdot 32$ & 0.06 & $-0.23,0.18$ & $0 \cdot 62$ \\
\hline Health & $-2 \cdot 31$ & $1 \cdot 28$ & $-2 \cdot 45$ & $1 \cdot 04$ & $-0 \cdot 16$ & $-0.33,0.00$ & 0.05 & $-0 \cdot 16$ & $-0.43,0.12$ & 0.23 \\
\hline WASH & $-2 \cdot 43$ & $1 \cdot 16$ & $-2 \cdot 12$ & $1 \cdot 15$ & 0.29 & $0.13,0.45$ & $<0.001$ & 0.33 & $0.08,0.59$ & 0.02 \\
\hline Integrated & $-2 \cdot 41$ & $1 \cdot 23$ & $-2 \cdot 41$ & $1 \cdot 11$ & -0.02 & $-0 \cdot 19,0 \cdot 15$ & 0.79 & -0.03 & $-0.47,0.41$ & $0 \cdot 88$ \\
\hline Comparison & $-2 \cdot 36$ & $1 \cdot 18$ & $-2 \cdot 34$ & $1 \cdot 17$ & - & & - & - & & - \\
\hline
\end{tabular}

WASH, water, sanitation and hygiene.

tAdjusted for child sex and age, mother's age, mother's mid upper-arm circumference and wealth group.

group. Improved access to vaccinations and supplements was observed in the WASH and nutrition education groups despite no specific intervention. There were significant reductions in use of the health centre to obtain vitamin A supplements and measles and BCG (Bacillus Calmette-Guérin) vaccinations in the health and integrated groups.

\section{Discussion}

The CCP project successfully delivered interventions over a 5-year period which resulted in an improvement in key knowledge, behaviours and use of key services to improve child health and nutrition.
A significant improvement in linear growth was observed only in the WASH intervention group. This was not, however, accompanied by improvements in other parameters usually associated with improved nutritional status. For example, the WASH group had the lowest improvement in mother's education, the lowest maternal nutritional status, the oldest carers (the occurrence of stunting is associated with increasing mother's age), a higher number of children in the older age group (stunting prevalence increases with age), a smaller increase in knowledge on causes and treatment of diarrhoea and the lowest improvement in dietary diversity (although seasonal differences may have been involved here). On the other hand, the WASH group showed a significant improvement in hygiene practice, the biggest and significant increase in coverage of measles vaccination, 
Comparison

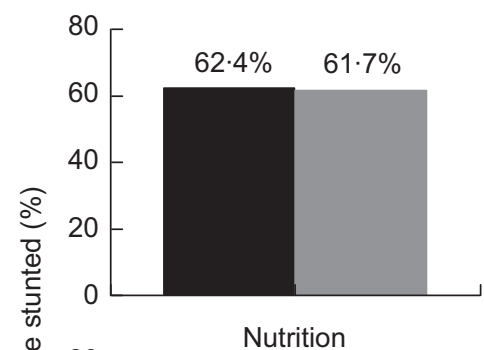

Health

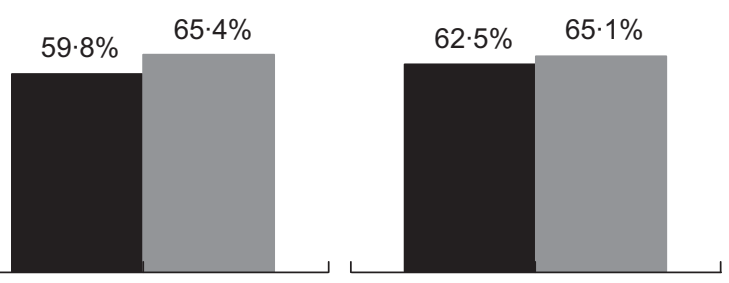

WASH

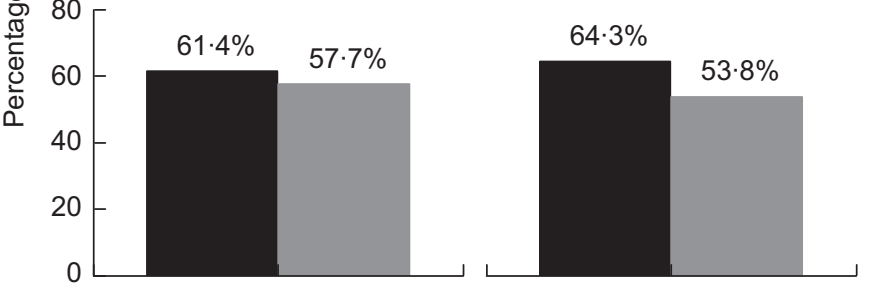

Fig. 2 Stunting prevalence at baseline (2004; $\square$ ) and evaluation (2009; $\square$ ) surveys in the intervention and comparison groups, children aged 6-36 months, Amhara, Ethiopia (WASH, water, sanitation and hygiene)

Table 4 Adjusted double differences between baseline and evaluation survey for each intervention group compared with the comparison group for secondary outcomes, Amhara, Ethiopia

\begin{tabular}{|c|c|c|c|c|}
\hline & \multicolumn{4}{|c|}{ Interventions } \\
\hline & Nutrition & Health & WASH & Integrated \\
\hline & Mean or \% & Mean or \% & Mean or $\%$ & Mean or $\%$ \\
\hline \multicolumn{5}{|l|}{ Health-seeking behaviour } \\
\hline \multicolumn{5}{|l|}{ Knowledge of diarrhoea } \\
\hline Mother's knowledge (mean)† & $+1 \cdot 31^{\star \star \star}$ & $+0.96^{\star \star \star}$ & $-0 \cdot 76^{\star \star \star}$ & $+1 \cdot 49^{\star \star \star}$ \\
\hline Cause of diarrhoea (mean)‡ & $+0 \cdot 36^{\star \star *}$ & $+0 \cdot 47^{\star \star \star}$ & $+0 \cdot 21^{\star \star *}$ & $+0 \cdot 45^{\star \star *}$ \\
\hline \multicolumn{5}{|l|}{ Health service utilisation (\%) } \\
\hline Diarrhoea treatment & $+2 \cdot 4$ & $+38 \cdot 5^{\star \star \star}$ & $+7 \cdot 6$ & $+39 \cdot 6^{\star \star \star}$ \\
\hline Fever treatment & $-3 \cdot 6$ & $+16 \cdot 5$ & $+0 \cdot 2$ & $+21 \cdot 7^{*}$ \\
\hline Cough treatment & $-4 \cdot 5$ & $+17 \cdot 2^{*}$ & $+6 \cdot 7$ & $+27 \cdot 6^{\star \star \star}$ \\
\hline Measles vaccination coverage & $+1 \cdot 2$ & $-6 \cdot 9^{\star}$ & $+9 \cdot 2^{\star \star}$ & +0.7 \\
\hline BCG coverage & $+6 \cdot 8^{*}$ & $-6 \cdot 4^{\star}$ & $-3 \cdot 8$ & $-12 \cdot 0^{\star \star \star}$ \\
\hline Vitamin A coverage & $+0 \cdot 7$ & $-14 \cdot 3^{\star \star \star}$ & $+4 \cdot 7^{*}$ & $+5 \cdot 4^{*}$ \\
\hline \multicolumn{5}{|l|}{ Improved infant \& young child feeding (\%) } \\
\hline Knowledge of complementary feeding & $+11 \cdot 1^{\star \star \star}$ & $+0 \cdot 8$ & $-1 \cdot 6$ & $+8 \cdot 5^{\star \star}$ \\
\hline Knowledge and practice of breast-feeding & $+0 \cdot 84^{\star * \star}$ & $+0.54^{\star * *}$ & $-0.89^{\star \star \star}$ & $+0.86^{\star \star *}$ \\
\hline \multicolumn{5}{|l|}{ Improved preventive practice } \\
\hline Dietary diversity (mean)§ & $-0 \cdot 10$ & -0.04 & $-0 \cdot 16^{* *}$ & +0.07 \\
\hline Hygiene (mean)\| & $-0.29^{\star \star}$ & $-0.25^{\star \star}$ & $+0 \cdot 34^{\star \star \star}$ & $-0 \cdot 39^{\star \star *}$ \\
\hline \multicolumn{5}{|l|}{ Improved access (\%) } \\
\hline Safe water & $-23 \cdot 1^{\star * \star}$ & $-11 \cdot 5^{\star \star \star}$ & $-11 \cdot 2^{\star \star \star}$ & $+9 \cdot 9^{\star \star \star}$ \\
\hline Toilet & $+7 \cdot 0^{\star \star \star}$ & +0.4 & -0.6 & $+10 \cdot 0^{\star \star \star}$ \\
\hline Soap & $-7 \cdot 7^{\star}$ & $-3 \cdot 8$ & $+4 \cdot 1$ & $+3 \cdot 1$ \\
\hline
\end{tabular}

WASH, water, sanitation and hygiene; BCG, Bacillus Calmette-Guérin.

Value was significantly different from that of the comparison site with robust standard errors adjusting for cluster at village level ( $\chi^{2}$ test for difference in proportions and $t$ test for difference in means): ${ }^{\star} P<0 \cdot 05,{ }^{\star \star} P<0 \cdot 01,{ }^{\star \star \star} P<0.001$.

tMother's knowledge score is a composite variable made from information about appropriate feeding practices and knowledge and treatment of diarrhoea. ‡Diarrhoea knowledge score is knowledge about the causes of diarrhoea.

$\S$ Dietary diversity adapted from Ruel scores.

$\|$ Hygiene score is a composite variable from observation of whether the household has a tap, a clean compound, presence of animal faeces and water storage covering facility.

-Access to safe water is water from a protected water source that takes less than 30 min return time.

and had a higher prevalence of girls in the older group (boys are generally more stunted than girls in Africa) ${ }^{(16)}$.

The WASH group also benefited from investment in the physical infrastructure and capacity development, as well as having the same community leader throughout the project; all other groups had a change of leader. These factors may have deepened community involvement and given a stronger sense of ownership, and sustainability, of 
the project. In this sense, community mobilisation could have contributed to minimising inequities in access and utilisation of services and better care of children.

The nutrition intervention group also experienced an increase in mean HAZ but the difference was not statistically significant. There is some evidence that nutrition education, particularly if delivered through effective behaviour change activities, can reduce stunting. A study in Peru to test the effectiveness of enhanced quality and coverage of nutrition education in health facilities found significant differences in stunting at 18 months of age compared with the control group ${ }^{(3)}$. The Lancet series on mother and child undernutrition concluded that education strategies alone were of most benefit in populations that had sufficient means to procure food. In populations without adequate food, educational interventions were of benefit when combined with food supplements ${ }^{(17)}$. The PSNP was delayed for 3 months on average over the life of the project and so was probably ineffective as a means of addressing food insecurity. Thus, the lack of difference in stunting prevalence through nutrition counselling alone is expected given the absence of other strategies to address food insecurity.

The health and integrated groups both showed smaller non-significant decreases in mean HAZ. These were unexpected findings and are not easily explained. One possible reason for the result found in the health group is that the delivery of free drugs was delayed and began halfway through the project due to logistical problems. This may not have been enough time to affect changes in linear growth. The integrated group received a large number of health and nutrition messages, which could have resulted in information overload and compromised the effectiveness of the services delivered. Without further in-depth studies or a repeat of this type of project, however, it is not possible to draw firm conclusions.

There were a number of limitations to the present study, many of which were outside the control of the project and have been described in more detail in a second paper on lessons learnt (to be published). There was continuous drought during the last 3 years of the project with no improvements in chronic food insecurity and loss of assets. There was contamination between the intervention and non-intervention groups as the Government's health extension workers were active in all areas and were spreading the same nutrition and health messages as were being given by the CCP project. There were a few other health, nutrition and WASH programmes set up during the 5-year period that the CCP project ran. While most of these programmes covered the whole district, some were run in specific villages. For example, the comparison group benefited from the presence of a local non-governmental organisation, Essential Services to Health in Ethiopia (ESHE), which was responsible for working with the health extension workers in delivering the Essential Nutrition Actions. However, part of the evaluation study was to establish such contamination and it was clear that nearly all households either received their information from the CCP programme or by the health extension workers who covered the entire district rather than through other organisations. One potential source of contamination may have been through the provision of hardware for the construction of springs and wells; and this happened in all but the nutrition villages. However, the demand for improved water sources was higher in the WASH group and the impact on stunting may have been due to the presence of any intervention, rather than the particular WASH intervention; as such, selection bias cannot be discounted from the interpretation.

The sample size for the evaluation was smaller than for the baseline and may in part be due to the Government's drive to reduce birth rate and the provision of free contraceptives in the area rather than substantial population shifts in what is considered a fairly stable area. Given that the sampling was exhaustive the stunting prevalence is representative of each area at that time. However, the effects of declining population rates and changes in demography could have had an independent impact on stunting prevalence which again may offer an important explanation for the findings of the study. Issues of sample size and number of clusters are further discussed in the lessons learnt paper.

Implementation problems were also an important consideration especially the high staff turnover within Save the Children UK that meant project management was adversely affected, while the late delivery of drugs due to logistical reasons meant that the health group did not receive the intervention long enough to observe an effect. Enumerators, while assigned to one specific intervention area, had access to all the training materials for the other intervention groups. This means they could have unwittingly given other information related to the other interventions. Another issue is that by staying with the same intervention group any systematic error in anthropometric measurements may have biased the data, although quality checks were put in place in the evaluation survey to ensure robust data collection and refresher training was carried out where necessary.

However, there is evidence from other studies that the interaction of water and sanitation with other health and nutrition outcomes will vary according to environmental conditions under which such studies are undertaken ${ }^{(9)}$. Studies elsewhere, although using different study designs, have shown that WASH interventions have a positive impact in reducing stunting in young children ${ }^{(9,18,19)}$. There is evidence that stunting incidence was $21 \%$ lower in Sudanese children with access to water and sanitation facilities than in those children with no access ${ }^{(9)}$. A study in Lesotho found evidence of an association between latrine ownership and attained height ${ }^{(18)}$.

These studies highlight that improved child growth is not only a food security issue but is also closely related to 
water, sanitation and hygiene. There is some evidence that tropical enteropathy (abnormalities of small bowel structure and function associated with malabsorption) is elevated in stunted children ${ }^{(20)}$ and is associated with chronic exposure to a variety of food- or water-borne micro-organisms, viruses, bacteria and protozoans ${ }^{(21)}$. A letter published in the Lancet discusses the evidence of the effect of poor sanitation and hygiene on linear growth and suggests substantial under-reporting of undernutrition due to the fact that an important causal pathway to malnutrition from poor hygiene and sanitation may be caused by tropical enteropathy and not just diarrhoea ${ }^{(22)}$. This suggests that improving hygiene practices could be a key element to preventing malnutrition in chronically food-insecure areas.

Despite the considerable challenges of conducting operations research in remote areas, the study has resulted in interesting findings that build the evidence base for effective mechanisms to address stunting. That the WASH group succeeded where other groups did not may be due to a combination of factors: better hygiene practice and increased community mobilisation, which were not present in the other areas. However, alternative reasons for this success cannot be ruled out. Further research is required to examine the impact of WASH on childhood stunting rates taking into consideration the context in which the study is set, as well as the explanation for the mechanisms through which WASH programmes work.

\section{Acknowledgements}

The CCP programme was a Save the Children programme in Legambo, Ethiopia, with funding initially from the UK Department for International Development for the first year and then Irish Aid for the following 4 years. The authors declare no conflict of interest. B.F. carried out the evaluation, cleaned and merged the data sets, analysed the data, and drafted and finalised the manuscript. A.T.B. was project manager during the final years of the CCP project, trained and supervised enumerators and survey staff, was responsible for data collection and data entry, and edited the manuscript. T.N. provided technical oversight to the project during implementation, managed logistics from Addis Ababa headquarters, and edited earlier drafts and the final manuscript. A.D. proposed the idea for the CCP study, carried out baseline data collection and analysis, and edited earlier drafts of the manuscript. F.W. provided comments and edited early drafts and the final manuscript. The authors acknowledge the Legambo field staff and Dessie office staff involved in the implementation and data collection of the CCP programme, especially Tayech Yimer (Nutrition Adviser), Kirros Tefera (ERP Nutritionist), Emkulu Yehayis (Relief Assistant Monitor), Mesfin Eshetu (Relief Assistant Monitor), Andargachew Eniyew (Health Project Officer), Tadesse Kidane (Driver), Mohamed Asfaw (Driver) and Matebie Fentie (Area Operations Manager).
The contributions of many other individuals who supported the implementation and evaluation of the CCP programme are also gratefully acknowledged, especially the participating members of the CCP communities. Thanks go also to the Legambo woreda Administration, Health and Agriculture offices. Finally, the authors acknowledge Dr Andrew Hall from Westminster University for his useful comments on an earlier draft of this manuscript.

\section{References}

1. Black RE, Allen LH, Bhutta ZA et al. (2008) Maternal and child undernutrition: global and regional exposures and health consequences. Lancet 371, 243-260.

2. Shrimpton R, Victora CG, de Onis M et al. (2001) Worldwide timing of growth faltering: implications for nutritional interventions. Pediatrics 107, e75.

3. Penny ME, Creed-Kanashiro HM, Robert RC et al. (2005) Effectiveness of an educational intervention delivered through the health services to improve nutrition in young children: a cluster-randomised controlled trial. Lancet 365, 1863-1872.

4. Merchant AT, Jones C, Kiure A et al. (2003) Water and sanitation associated with improved child growth. Eur J Clin Nutr 57, 1562-1568.

5. Save the Children UK (2008) Annual Impact Assessment of the Child Caring Practices Project in Legambo District, Ambara Region, Ethiopia. London: Save the Children UK.

6. SCN Task Force on Assessment, Monitoring and Evaluation (2008) Establishing stunting as an additional indicator of endemic poverty to monitor progress made towards the achievement of MDG 1. Draft Statement from the SCN Task Force on Assessment, Monitoring \& Evaluation. http:// www.unsystem.org/scn/Publications/html/statements.htm (accessed October 2009)

7. Save the Children UK (2002) Wealth, Health \& Knowledge: Determinants of Malnutrition in North Wollo. London: Save the Children UK.

8. Sharp K, Devereux S \& Amare Y (2003) Destitution in Ethiopia's Northeastern Highlands (Ambara National Regional State). Final Report. Brighton/London: Institute of Development Studies/Save the Children UK.

9. Regional Hunger and Vulnerability Programme (2007) Lessons from Ethiopia on a scaled-up national safety net programme. Wahenga Brief no. 14, August 2007.

10. Pathfinder International/Ethiopia (2008) Ethiopia's Health Extension Program: Pathfinder International's Support 2003-2007. Addis Ababa: Pathfinder International/Ethiopia.

11. Fenn B (2009) Legambo Child Caring Practices Project Legambo District, Amhara, Ethiopia: Final Impact Evaluation. London: Save the Children UK.

12. WHO Multicentre Growth Reference Study Group (2006) WHO Child Growth Standards: Length/Height-for-Age, Weight-for-Age, Weight-for-Length, Weight-for-Height and Body Mass Index-for-Age: Methods and Development. Geneva: WHO.

13. SMART (Standardized Monitoring \& Assessment of Relief \& Transitions) (2006) Measuring Mortality, Nutritional Status, and Food Security in Crisis Situations: SMART METHODOLOGY. http://www.smartindicators.org/SMART_Methodology_0807-2006.pdf (accessed May 2009).

14. ENA (2009) Software for Emergency Nutrition Assessment. http://www.nutrisurvey.de/ena_beta/ena-epiinfo/index.htm (accessed October 2009).

15. Ruel MT \& Menon P (2002) Creating A Child Feeding Index Using the Demographic and Health Surveys: An Example from Latin America. FCND Discussion Paper no. 130. Washington, DC: IFPRI. 
16. Wamani H, Astrøm AN, Peterson S et al. (2007) Boys are more stunted than girls in Sub-Saharan Africa: a metaanalysis of 16 demographic and health surveys. BMC Pediatr 7, 17.

17. Bhutta ZA, Ahmed T, Black RE et al. (2008) What works? Interventions for maternal and child undernutrition and survival. Lancet 371, 417-440.

18. Daniels DL, Cousens SN, Makoae LN et al. (1991) A study of the association between improved sanitation facilities and children's height in Lesotho. Eur J Clin Nutr 45, 23-32.
19. Ulijaszek S (2000) Nutrition, infection, and child growth in Papua New Guinea. Coll Antropol 24, 423-429.

20. Goto R, Panter-Brick C, Northrop-Clewes CA et al. (2002) Poor intestinal permeability in mildly stunted Nepali children: associations with weaning practices and Giardia lamblia infection. Br J Nutr 88, 141-149.

21. Menzies IS, Zuckerman MJ, Nukajam WS et al. (1999) Geography of intestinal permeability and absorption. Gut 44, 483-489.

22. Humphrey JH (2009) Child undernutrition, tropical enteropathy, toilet, and handwashing. Lancet 374, 1032-1035. 